DOI: $10.1515 /$ pts-2016-0026

\title{
MAGNETITE NANOPARTICLES PREPARED BY SPARK EROSION
}

\author{
M. Maiorov ${ }^{1}$, E. Blums ${ }^{1}$, G. Kronkalns ${ }^{1}$, A. Krumina ${ }^{2}$, M. Lubane ${ }^{2}$ \\ ${ }^{1}$ Institute of Physics, University of Latvia, \\ 32 Miera Str., Salaspils, LV2169, LATVIA \\ ${ }^{2}$ Institute of Inorganic Chemistry, Riga Technical University, \\ 32 Miera Str., Salaspils, LV2169, LATVIA \\ e-mail:maiorov@sal.lv
}

\begin{abstract}
In the present research, we study a possibility of using the electric spark erosion method as an alternative to the method of chemical co-precipitation for preparation of magnetic nanoparticles. Initiation of high frequency electric discharge between coarse iron particles under a layer of distilled water allows obtaining pure magnetite nanoparticles.
\end{abstract}

Keywords: diffraction, dynamic light scattering, magnetite, nanoparticle, superparamagnetic, X-ray.

\section{INTRODUCTION}

Nanomedicine is one of the promising trends in the modern treatment methods. Due to very high specific surface of dispersed material in colloids, coating of nanoparticles with medicines allows significantly reducing their concentration in treatment, thereby eliminating the problems related to resistance of antibiotics. Magnetic nanoparticles attract special interest because they allow realizing the magnetic drug targeting or the magnetic hyperthermia. For this purpose, superparamagnetic iron oxide nanoparticles (SPIONs) are chosen [1], [2] due to their chemical inactivity. The nanoparticles as precursors are usually prepared employing various chemical methods (co-precipitation, sol-gel method, hydrothermal method, thermal decomposition). For some applications, such a technology is unacceptable because the prepared nanodispersions may contain various uncontrollable chemical side products. To obtain the magnetic nanoparticles without use of chemicals they may be prepared by initiation of high frequency electric discharge between the coarse particles of ferromagnetic metals under a layer of dielectric liquid. This results in vaporization of the metal and subsequent vapour condensation in the form of nanoparticles (Svedberg method). Such a method has been used elsewhere to prepare ferrofluids [3], [4]. In the present research, we initiate the spark erosion of iron particles that are dispersed in distilled water. In such a way, the electrically vaporized iron and water condense together as SPIONs without any side products. 


\section{EXPERIMENT}

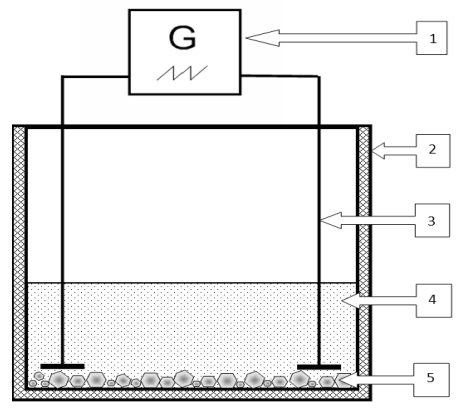

Fig. 1. Spark erosion set. 1 - spark generator, 2 - glass vessel, 3 electrode, 4 - water, 5 -metallic particles.

The principal sketch of experimental facility is shown in Fig. 1. Thin layer of the coarse metal particles is placed on the bottom of a dielectric vessel (glass). In our experiments, we employ a pure iron powder (pharmaceutical iron Ferrum reductum) that contains particles of sizes ranging between 0.3 and $1.5 \mathrm{~mm}$. The form of particles is shown in Fig. 2. The vessel is filled by distilled water. Flat steel electrodes that are in contact with the powder layer on bottom are connected to an electric spark generator. In our experiments, we used the spectrometric spark discharge generator UBI-1. Its principal circuit is shown in Fig. 3.

Adjusting the elements of discharge generator - the resistances R1 and R2, the condenser $\mathrm{C} 1$ and the inductor $\mathrm{L}$ - allows setting the mean current, the duration and the energy of discharge.

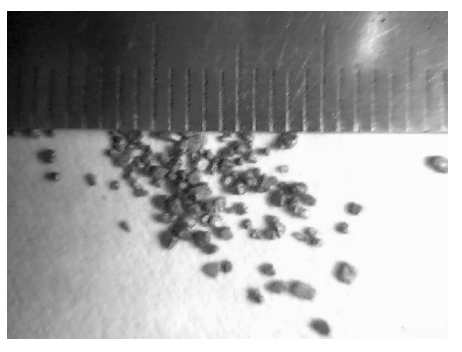

Fig. 2. Initial iron powder.

After switching on the generator, sparks appear between metal coarse particles that are suspended in a layer on bottom of the vessel. During approximately $10-20 \mathrm{~min}$, the liquid in vessel gradually becomes black due to formation of nanoparticle colloidal dispersion. After that time, the colloid was separated from initial metallic coarse particles by decantation. The obtained dispersion in water is not stable, during some hours the nanoparticles precipitate on bottom of the

flask. If shaking up the water suspension with hydrocarbon, in which a small amount of oleic acid is dissolved, the nanoparticles extract from water to the hydrocarbon. Oleic acid acts as a surfactant; therefore, the peptized nanodispersion is sedimentation-stable, and nanoparticles precipitation do not appear.

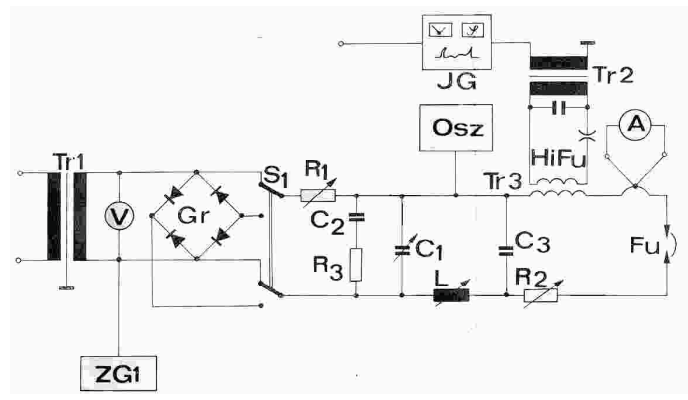

Fig. 3. Electric discharge generator UBI-1 (spark mode). A - discharge current meter, $\mathrm{C}_{1}-$ spark capacitor, $\mathrm{C}_{2}$ - capacitor of filter, $\mathrm{C}_{3}$ - capacitor of high frequency loop, $\mathrm{Fu}$ - main discharger, $\mathrm{Gr}-$ $\mathrm{AC} / \mathrm{DC}$ converter, $\mathrm{HiFu}$ - launching discharger, JG - launching generator, $\mathrm{L}$ - spark loop inductance,

Osz - oscillograph, $\mathrm{R}_{1}$ - current regulator, $\mathrm{R}_{2}$ - spark loop resistor, $\mathrm{R}_{3}$ - resistor of filter, $\mathrm{S}_{1}-\mathrm{AC} /$

DC switch, $\operatorname{Tr}_{1}-$ power transformer, $\operatorname{Tr}_{2}$ - pulse transformer, $\operatorname{Tr}_{3}$ - transformer of launch pulse, $\mathrm{V}-$ voltmeter. 


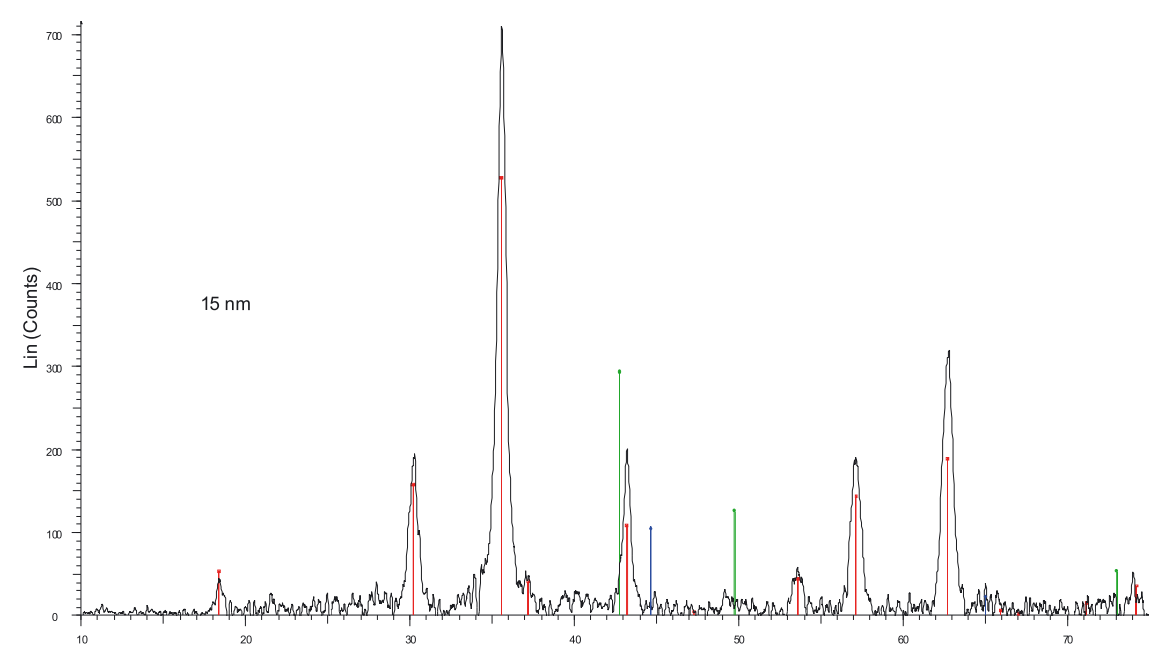

Fig. 4. X-ray diffraction of nanoparticles precipitated from water suspension. Red lines - the magnetite peaks, green lines and blue lines - the metallic iron peaks.

The properties of the product were studied by various methods. We performed X-ray diffraction spectra measurements by the diffractometer D8 Advance (Bruker Corporation) with $\mathrm{CuK} \alpha$ radiation $(\lambda=1.5418 \AA)$. Spectral distribution of measured pikes was used to detect the chemical structure of eroded nanoparticles, whereas the form of diffraction pikes allowed evaluating the particle mean size by Scherer method. The particle size was also analysed by translation electronic microscopy data (TEM) obtained by the JEOL JEM 1230 operating at $100 \mathrm{kV}$. Additionally, the particle size distribution was analysed by employing indirect methods from the dynamic light scattering data measured by Zetasizer Nano instrument Nano S90 ZEN1690, as well as from the magnetization curves measured at room temperature by vibration sample magnetometer (Lake Shore Cryotronics, Inc., model 7404) with a maximum magnetic field of $1 \mathrm{~T}$.

\section{RESULTS}

X-ray diffraction spectrum of nanoparticles that are precipitated from water suspension by decantation from the entire dispersion with coarse particles is shown in Fig. 4. All peaks are identified as belonging to magnetite; no metallic iron peaks are detected. It means that due to high temperatures, the electrically molten metal in sparks chemically reacts with the simultaneously vaporized water and, therefore, after solidification the nanoparticles consist of ferrous oxides, in our case - of magnetite. Form of diffraction peaks allows evaluating the particle size. According to Sheerer method, the widening of peaks corresponds to particle size of about $15 \mathrm{~nm}$.

Figure 5 depicts the magnetization loop of dry powder of nanoparticles. No coercivity is observed, the magnetic saturation of powder is about $60 \mathrm{emu} / \mathrm{g}$. It corresponds to approximately $60 \%$ bulk magnetite [5]. Nanometer sized particles have superparamagnetic properties. Summary magnetization curve of polydisperse particle suspensions may be considered superposition of Langevin functions of their various sub-fractions. The obtained oleic acid-coated nanoparticle dispersion in tet- 
radecane is stable enough to allow performing the analysis of magnetization curve by decomposition it on a sum of Langevin functions of various size subfractions (the magnetogranulometry procedure [6]). The obtained particle "magnetic size" distribution is shown in Fig. 6. The volume distribution mode is $9 \mathrm{~nm}$; the full distribution width at half maximum is $5.5 \mathrm{~nm}$. For a comparison, Fig. 6 presents the results of particle size distribution found from the analysis of particle Brownian motion in the hydrocarbon-based suspension by Dynamic Light Scattering (DSL) measurements [7]. As it is seen, the obtained values (volume distribution mode $8.9 \mathrm{~nm}$ and full distribution width at half-maximum $4 \mathrm{~nm}$ ) agree very well with the results of magnetogranulometry procedure listed above.

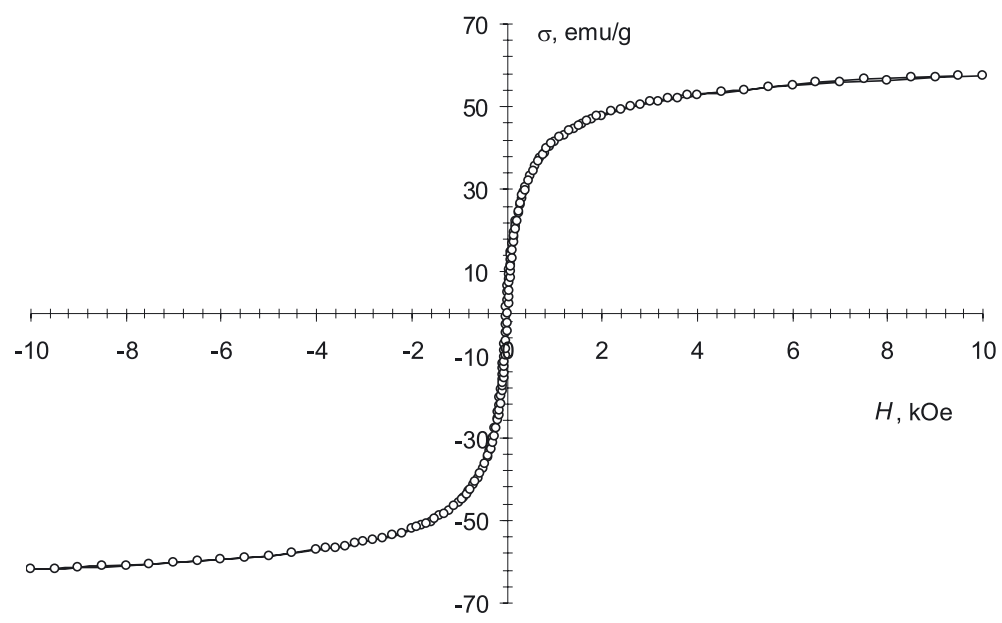

Fig. 5. The magnetization loop of the nanoparticle dry powder.
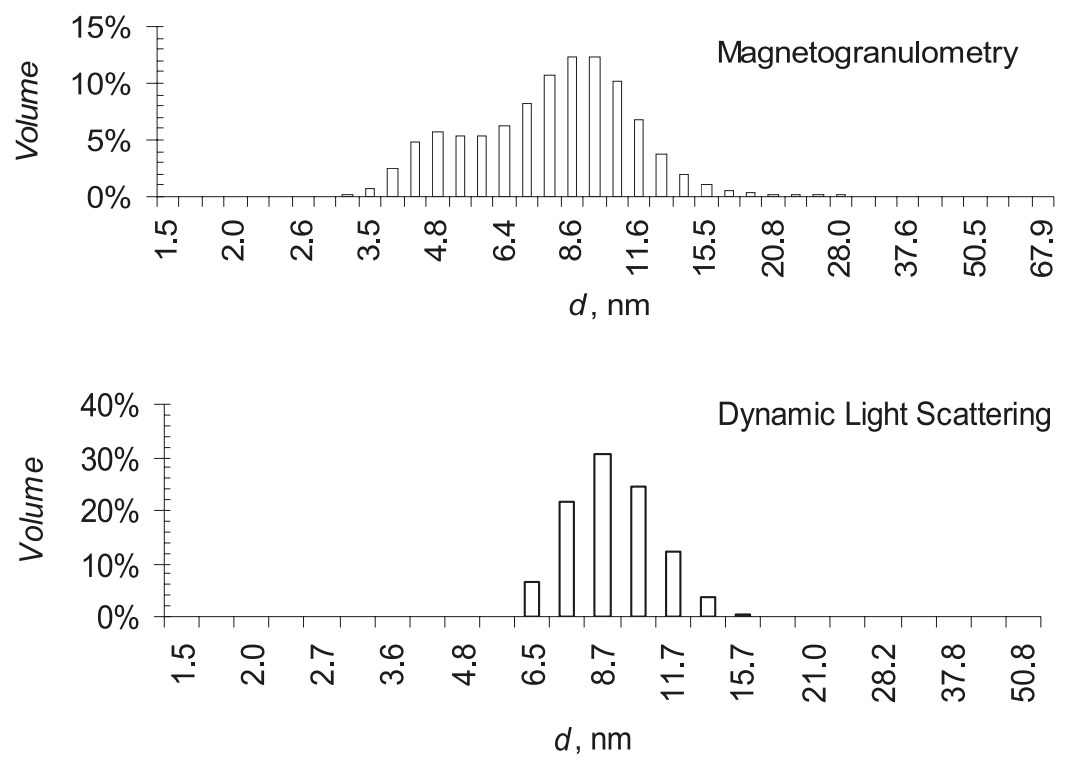

Fig. 6. The particle "magnetic" size distribution according to magnetoranulometry data (above) and the "physical" size distribution found from DLS measurements (below). 


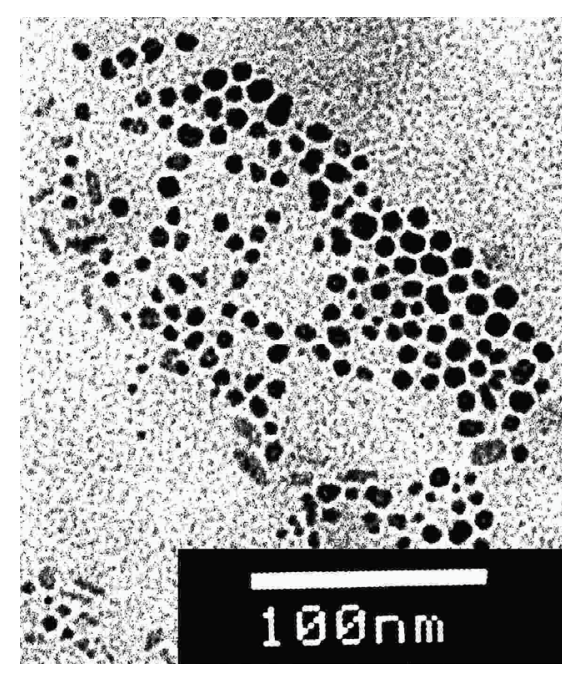

Fig. 7. TEM picture of nanoparticles dispersed in tetradecane.

Figure 7 presents the picture of nanoparticles suspended in tetradecane. As it is seen, the particle size ranges in the interval from $3 \mathrm{~nm}$ to $15 \mathrm{~nm}$. This result also agrees relatively well with those obtained from magnetogranulometry analysis and from DSL measurements.

It would be of a special interest to obtain pure metal nanoparticles by the Swedberg method. Unfortunately, as a rule, the spark erosion in liquids is accompanied by formation of various compounds (usually carbides in alcohols and in other hydrocarbons). Our preliminary experiments say that pure iron nanoparticles may be obtained by employing argon as the dispersion media. However, the stabilization of particle dispersions in any liquid is problematic due to extremely high chemical activity of nano-sized iron.

\section{CONCLUSION}

The use of the Svedberg method for dispersing of metallic iron in water allows obtaining magnetic nanoparticles, which consist of magnetite due to chemical interaction of molten metal with the evaporated water in sparks during the condensation and solidification. The extraction of nanoparticles from water to hydrocarbon solvent with oleic acid as surfactant creates stable colloidal solution with superparamagnetic properties. The particle sizes that are detected by different methods (TEM, XRD, DLS and magneto granulometry) have almost identical values. The particle size distribution is sufficiently narrow.

\section{ACKNOWLEDGEMENTS}

The research has been supported by the Latvian Science Foundation, Project 286/2012 and by the Latvian State Research Programme IMIS-2. 


\section{REFERENCES}

1. Tartaj, P., Morales M. P., Veintemillas-Verdaguer, S., Gonzalez-Carreno, T., and Serna, C. J. (2003). The preparation of magnetic nanoparticles for applications in biomedicine. J. Phys. D: Appl. Phys. 36, R182-R197.

2. Mahmoudi, M., Sant, S., Wang, B., Laurent, S., and Sen, T. (2011). Superparamagnetic iron oxide nanoparticles (SPIONs): Development, surface modification and applications in chemotherapy. Advanced Drug Delivery Reviews. 63, 24-46.

3. Mozgovoi, E., N., and Blum, E. Ya. (1971). Magnetic properties of finely dispersed ferrosuspensions synthesized by the electrical condensation method, Magnetohydrodynamics (Engl. Transl.). 7, (4), 448-453.

4. Berkowitz, A. E., and Walter, J. L. Ferrofluids prepared by spark erosion. (1983). Journal of Magnetism and Magnetic Materials. 39, (1-2), 75-78.

5. Bozorth, R. (1951). Ferromagnetism. Toronto-New York-Landon: Van Norstand.

6. Maiorov, M. M., Blums, E., and Raj, K. (2010). Inverse task for evaluation of particle size distribution of polydisperse magnetic fluids. (12th International Conference on Magnetic Fluids). Physics Procedia. 9, 74-77.

7. Tech Note: Dynamic Light Scattering: An Introduction. Available at http://www.malvern.com

\section{DZIRKSTS EROZIJAS PROCESĀ IEGŪTĀS MAGNETITTA NANODAL̦IN,AS}

M. Maiorov, E.Blūms, G. Kroṇkalns, A.Krūmiņa, M. Lubāne

Kopsavilkums

Darbā tiek pētīta iespēja izmantot elektriskās dzirksts erozijas metodi kā alternatīvu ķīmiskās izsēdināšanas metodei, lai iegūtu magnētiskas nanodaḷiņas. Inicējot augstas frekvences elektrisko dzirksti starp dzelzs dalināām ūdens suspenzijā, tiek iegūtas tīra magnetīta nanodalịinas.

17.03.2016. 